\begin{tabular}{l} 
SCIENCE \& TECHNOLOGY \\
Journal homepage: http://www.pertanika.upm.edu.my/ \\
\hline PERTANIKA
\end{tabular}

\title{
Empirical Model of Ground-Borne Vibration Induced by Freight Railway Traffic
}

\author{
Mohd Khairul Afzan Mohd Lazi*, Muhammad Akram Adnan and Norliana Sulaiman \\ School of Civil Engineering, College of Engineering, University of Technology MARA, 40450 UiTM, \\ Shah Alam, Selangor, Malaysia
}

\begin{abstract}
Developing an empirical model that can predict ground-borne vibration is required in the modelling process using actual data of ground vibration velocity induced by train traffic collected from sites. In the preliminary and mitigation planning stages of the project, the empirical models developed are expected to predict the ground-borne vibration velocity due to rail traffic. The findings of this research are expected to provide a new perspective for railway planners and designers to improve the national design to improve the quality of life for the residents living close to the rail tracks. This research study firmly fills the information gap towards a fundamental understanding of ground-borne vibration in numerous areas of learning regarding the condition of train operation. This study has developed a prediction model of regression to forecast the peak particle velocity of groundborne vibration from freight trains based on correlated and fixed parameters. The models developed have considered a few parameters obtained from sites using minimal or without tools altogether. Speed of trains and distance of receivers from the sources were the only significant parameters found in this study and used to simplify the empirical model. Type of soil, which is soft soil, and type of train, which is freight train, were the fixed parameters for this study. The data collected were measured along the ground rail tracks involving human-operated freight trains. Residents from the landed residential areas near the railway tracks were chosen as the receivers. Finally, the peak particle velocity models have been successfully developed, and validation

ARTICLE INFO

Article history:

Received: 20 December 2020

Accepted: 03 April 2021

Published: 31 July 2021

DOI: https://doi.org/10.47836/pjst.29.3.21

E-mail addresses:

analysis was conducted. The model can be used by authorities in the upcoming plan for the new rail routes based on similar fixed parameters with correlated parameters from the study.
\end{abstract}

tmm_afxan@yahoo.com (Mohd Khairul Afzan Mohd Lazi) akram@uitm.edu.my (Muhammad Akram Adnan)

norliana545@uitm.edu.my (Norliana Sulaiman)

* Corresponding author
Keywords: Empirical model, freight train, groundborne vibration, peak particle velocity 


\section{INTRODUCTION}

At present, many regulatory institutions, such as the Union of International Railways (UIC), are demanding the establishment of standard prediction models that can predict vibration impact towards human perception (Hermsworth, 2000). Sulaiman (2018) stresses the importance of developing Malaysia's own vibration limits and local conditionsbased control guidelines, as most developed countries already have their own vibration measurement and design requirements. Lazi et al. (2016) also emphasize the importance of establishing Malaysia's own standard based on the local geological conditions especially in the development of public transportation infrastructure.

In various stages of railway design processes and in the evaluation of vibration countermeasures, the establishment of ground-borne prediction models can be used as a predictive tool. Practitioners, particularly local authorities, can use the models at planning stage and provide mitigation suggestions, if necessary, at railway system development stage.

Maintenance of tracks may also be expensive because of the excessive vibration in the rail track structure. The instrument that can be properly used at various stages of the railway design process, including planning for environmental impact assessment, would be a ground vibration prediction model (Bahrekazemi, 2004). In assessing and evaluating the issue of ground-borne vibration, as in Germany and the United Kingdom, most developed countries have their own standards, including the development of guidelines and standards for the assessment and measurement of structural and human ground vibration, such as the Deutsches Institut für Normung (1999), the International Standard Organization (ISO, 1997), and the British Standard (2008). Malaysia has Vibration Limits and Environmental Control Guidelines developed by the Department of Environment Malaysia (2007) from the Ministry of Natural Resources and Environment Malaysia. The guidelines were established to define the appropriate limits for quantitative evaluation of ground vibration. However, the guidelines only define the levels of vibration and no system or equipment is specified to predict or calculate the degree of ground vibration. The only instruments recommended to calculate the vibration level are seismographs and geophones. The affordability of such equipment is the major concern among relevant Malaysian authorities (Sulaiman, 2018). This study attempts to develop a regression model to predict the peak particle velocity of ground-borne vibration induced by freight trains to minimize the dependency on vibration equipment.

To satisfy industrial requirements, such as the operation of public transportation, it is very important to establish guidelines and regulations. This research attempts to generate an empirical model that represents ground-borne vibration based on the condition and parameters of freight rail traffic in Malaysia. In this analysis, the empirical model has the potential to become the basis of the ground-borne vibration prediction tool using simple parameters for future use by related practitioners. 
This research study is intended to bridge the knowledge gap about the basic understanding of ground-borne vibration, consisting of a combination of many branches of learning on the state of local rail transportation. Limited findings regarding the level of perceived irritability and annoyance experienced by affected people living near the source of vibrations especially in Malaysia have become the motivation of this study. The study also develops a prediction model of vibration velocity from freight trains. The empirical model produced can predict the ground-borne vibration velocity using local rail traffic parameters. The basic parameters applied in this study have the potential to reduce the dependency on expensive equipment.

\section{LITERATURE REVIEW}

\section{Propagation}

Typically, after ground-borne vibrations are produced, they propagate to the surrounding area through the soil medium. Propagation characteristics depend on the properties of the soil, parameters, and distance from the source. Compared to stiff or hard ground, soft ground appears to have lower frequency. Soil vibration can travel longer distances from its source at low frequencies. The main factor influencing significant ground vibration is soft soil formation, such as silt or soft clay, which can cause discomfort for individuals living 100 to $200 \mathrm{~m}$ away from the rail tracks (Madshus et al., 1996).

The major impact of the soil form on the propagation of ground vibration is shown in Figure 1 (Hajek, 2006), showing how the frequency of soil absorption results in the attenuation of ground vibration. Although this result is from road traffic analysis, the characteristics of different types of soil are clearly demonstrated in terms of vibration velocity and distance to the edge of the pavement. The highest vibration absorption capacity is found in gravel soils and dry sand, while the lowest is peat or soft clay (Watts, 1990). As a result, ground vibration will be rapidly attenuated as the distance along the path of

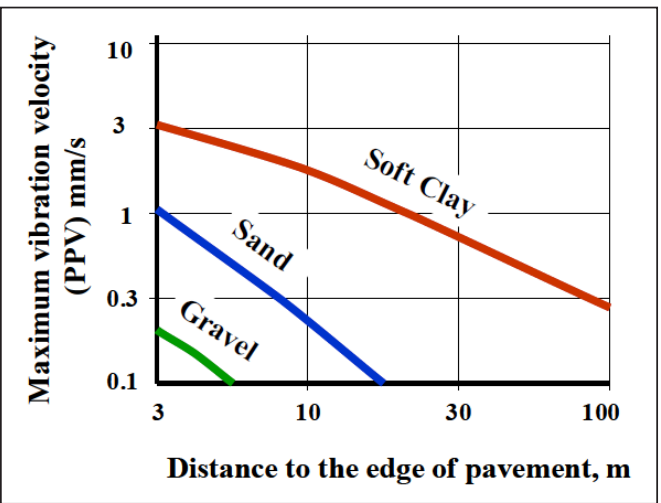

Figure 1. Ground vibration propagation in different types of soil (Hajek, 2006) ground transmission increases (Hunt \& Hussein, 2007). In summary, compared to soft soil, ground vibration in a stiff or hard soil could be attenuated and absorbed much more quickly with distance.

The path of propagation could also be affected by refractions and reflections at the interface between soil and the bedrock and between soil layers. Refraction and reflection could lead to a wave's propagation which deviates from its original path to the receiver. Persson (2016) also reported that 


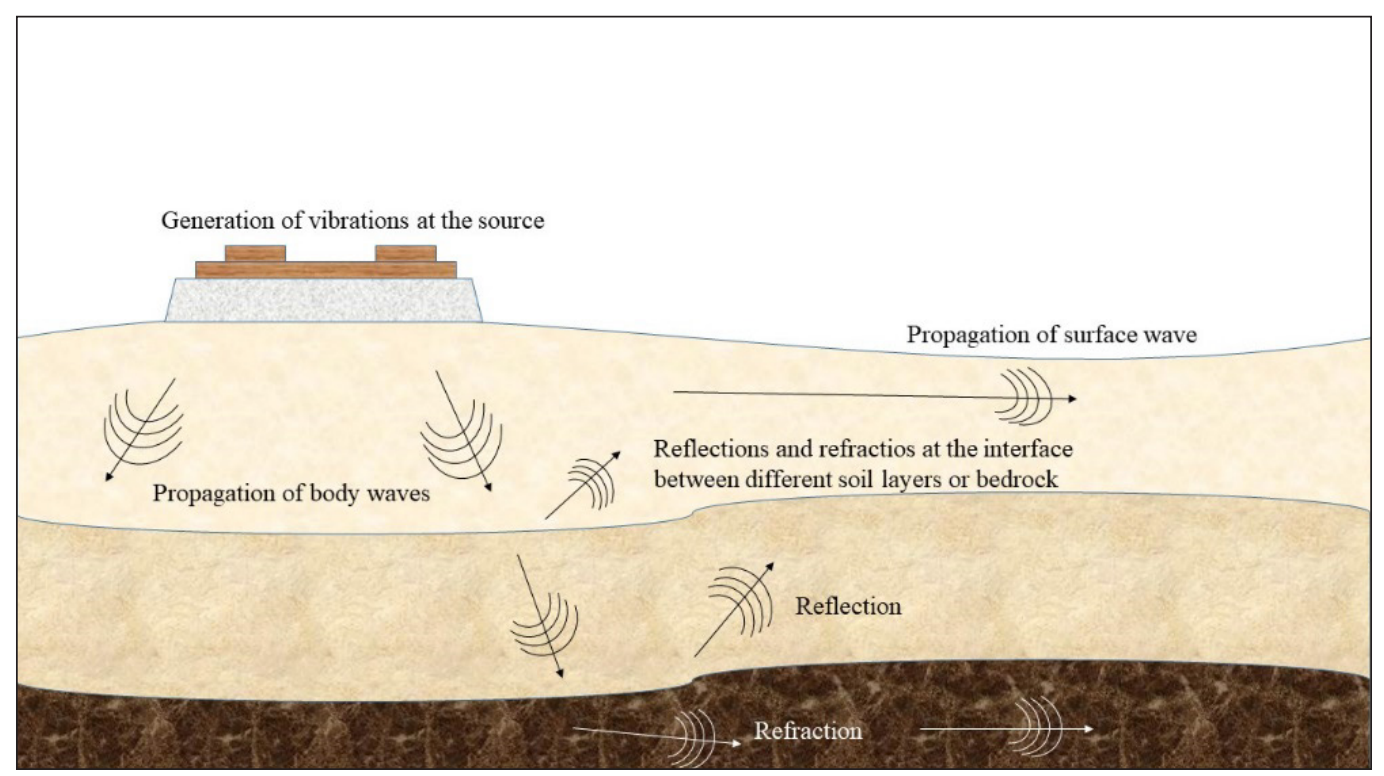

Figure 2. Propagation movement for ground vibration (Persson, 2016)

the propagation velocity for each wave form is controlled by the conditions of the ground soil, as shown in Figure 2.

There are several ways available to determine a vibration's magnitude. Velocity, displacement, and acceleration are the three most common forms of measuring vibrations (Eitzenberger, 2008). The standard unit for velocity is $\mathrm{mm} / \mathrm{s}$, while displacement is $\mathrm{mm}$, and acceleration is $\mathrm{mm} / \mathrm{s}^{2}$. Velocity is used in this analysis as the values need to be compared to the values used by the standard Malaysian guidelines. The standard guidelines use velocity as the vibration magnitude. The vibration rate is determined by the Peak Particle Velocity (PPV), and it is the most recognized and used vibration measurement. Vibration limits using PPV are recommended by most guidelines and regulations. The maximum particle velocity over the total recorded time is regarded as the peak particle velocity for each recorded waveform as shown in Figure 3 (Alcudia et al., 2007).

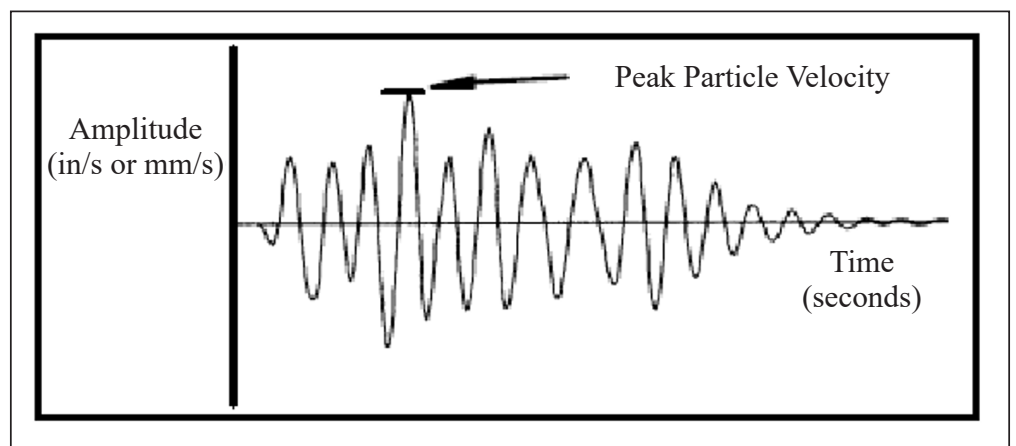

Figure 3. The definition of Peak Particle Velocity (Alcudia et al., 2007) 
The PPV is the maximum instantaneous velocity of a particle at a point in a particular time interval. Ground particles vibrate with varying particle velocities when the disturbance from the source of vibrations propagates away from the source with a certain amount of wave velocity. The motion at a given location along the propagation path is represented in three mutually perpendicular components (usually transverse, vertical, and radial or longitudinal). All three components must be calibrated at the same time to ensure the PPV is correctly determined (Avellan et al., 2017). For this study, the PPV was determined as the vibration velocity to be measured.

\section{Vibration Monitoring Technology}

Vibration can be detected using a range of sensors. There are sensors designed to measure velocity, acceleration, and displacement based on various types of vibrations, using various measuring technologies, such as microelectromechanical systems or known as MEMS sensors, piezoelectric or PZT sensors, laser Doppler vibrometers, and proximity probes. When deformed, PZT sensors, the most widely used sensors, produce voltages. The vibrations can be interpreted by digitalizing and decoding the voltage signals. The vibration levels and maximum frequency range, as well as other operating environment variables including humidity, temperature, and $\mathrm{pH}$ level, should all be considered when choosing vibration sensors (Huang, 2016).

A MEMS sensor is a 3-axis acceleration device with sensitivity in the low-frequency and low-acceleration regions, and its peripheral circuitry is developed. A prototype is built to enable constant measurement of micro-vibrations (Sakaue et al., 2012). For the laser Doppler vibrometer, the angle that the target surface creates with the vibrometer's laser signal is used to determine the transverse displacement, and the change in velocity is read as vector quantity by the laser Doppler vibrometer. When the target surface is perpendicular to the laser, the vibrometer's output reads the same transverse displacement (Garg, 2017).

\section{Review of Prediction Model from Railway Traffic}

In the past 30 years, many models have been produced to predict the ground-borne vibrations caused by rail traffic. Table 1 shows a description with independent variables for the predictor variables used in the previously established vibration models for trains.

The prediction models produced by previous researchers were based on the original geological condition and environment study area. The models were developed to predict the velocity of vibration involved with complex parameters. The parameters selected required practitioners to obtain data from service providers or need to have special equipment to get the data. As a summary, the parameters as independent variables include velocity vector, speed factor, distance factor, track quality factor, building amplification factor, and wheel force. The factors or elements used in the previous models are simplified in this research 
Table 1

Previous models of ground-borne vibration induced by trains

\begin{tabular}{|c|c|c|c|}
\hline Author/Year & $\begin{array}{l}\text { Study } \\
\text { origin }\end{array}$ & Model & Description \\
\hline $\begin{array}{l}\text { Madshus et } \\
\text { al. (1996) }\end{array}$ & Norway & $\mathrm{V}=V_{T} F_{S} F_{D} F_{R} F_{B}$ & $\begin{array}{l}\mathrm{V} \text { is the peak particle velocity in } \mathrm{mm} / \mathrm{s} \text {. } \\
V_{T} \text { is the specific vibration level for } \\
\text { specific train types. } \\
F_{S} \text { is the speed factor. } \\
F_{D} \text { is the distance factor. } \\
F_{R} \text { is the track quality factor. } \\
F_{B} \text { is the building amplification factor. }\end{array}$ \\
\hline $\begin{array}{l}\text { Jones and } \\
\text { Block (1996) }\end{array}$ & England & $\begin{array}{l}V_{D k}=F_{D}(f) X_{D k} \\
X_{D k}=\left(\sum_{j=-\infty}^{\infty} x_{j k}^{2}(f)\right)^{1 / 2} \\
x_{j k}(f)=\sum_{l=0}^{N} a_{j l} P_{l}\left(\cos \theta_{j}\right)\end{array}$ & $\begin{array}{l}\text { The models are only applicable for freight } \\
\text { trains. } V_{D k} \text { is the vertical vibration } \\
\text { predicted. } \\
X_{D k} \text { is the total transfer function. } \\
F_{D}(f) \text { is the vertical vibration for sleeper. } \\
x_{j k} \text { is the energy sum of the transfer } \\
\text { function. } \\
\mathrm{k}=0 \text { is the vertical response function and } \\
\mathrm{k}=1 \text { is the lateral. } \\
\boldsymbol{\theta} \text { is the angle between the normal to the } \\
\text { track at the response position and the } \\
\text { excitation point on the track. }\end{array}$ \\
\hline $\begin{array}{l}\text { Suhairy } \\
(2000)\end{array}$ & $\begin{array}{l}\text { Southern } \\
\text { Sweden }\end{array}$ & $\mathrm{V}=\mathrm{V}_{\mathrm{T}}{ }^{*}\left(\frac{\mathrm{D}}{\mathrm{D}_{0}}\right)^{\mathrm{B}} *\left(\frac{\mathrm{S}}{\mathrm{S}_{0}}\right)^{\mathrm{A} *} \mathrm{~F}_{\mathrm{R}}{ }^{*} \mathrm{~F}_{\mathrm{B}}$ & $\begin{array}{l}\text { This equation could be used to find the } \\
\text { vibration rates for various types of trains } \\
\text { at different distances. } \\
\mathrm{V} \text { is vibration velocity in mm/s. } \\
\mathrm{V}_{\mathrm{T}} \text { is measure vibration levels for the } \\
\text { trains. } \\
\mathrm{D} \text { is distance from the centre of track. } \\
\mathrm{D}_{\mathrm{o}} \text { is reference distance. } \\
\mathrm{S} \text { is train speed. } \\
\mathrm{S}_{\mathrm{O}} \text { is reference speed. } \\
\mathrm{B} \text { is distance dependent. } \\
\mathrm{A} \text { is speed dependent exponential. } \\
F_{R} \text { is the track quality factor. } \\
F_{B} \text { is the building amplification factor. }\end{array}$ \\
\hline $\begin{array}{l}\text { Jiang and } \\
\text { Zhang (2004) }\end{array}$ & Shanghai & $\mathrm{VL}=70-13.6 \log (\mathrm{r} / 10)$ & $\begin{array}{l}\text { VL is vibration level. } \\
\mathrm{r} \text { is the distance from the viaduct line's } \\
\text { centre in } \mathrm{m} \text {. }\end{array}$ \\
\hline $\begin{array}{l}\text { Bahrekazemi } \\
(2004)\end{array}$ & Sweden & $\mathrm{V}=($ a.speed $+b)\left[\frac{r}{r_{0}}\right]^{-n}$ & $\begin{array}{l}\mathrm{V} \text { is the particle velocity on the track. } \\
\mathrm{a} \text { and } \mathrm{b} \text { are the parameters of the model. } \\
\mathrm{n} \text { is attenuation power. } \\
\mathrm{R} \text { is the source distance from the receiver. } \\
\mathrm{r}_{0} \text { is the reference distance. }\end{array}$ \\
\hline $\begin{array}{l}\text { With et al. } \\
(2006)\end{array}$ & Sweden & $v_{r m s}=\left(a_{1} F_{r m s}+a_{2}\right) \mathrm{V}+\left(b_{1} F_{r m s}\right.$ & $\begin{array}{l}v_{r m s} \text { is the r.m.s particle velocity. } \\
\mathrm{V} \text { is speed of train. } \\
F_{r m s} \text { is the r.m.s. wheel force applied. } \\
a \text { is the gradient. } \\
b \text { is the intercept. }\end{array}$ \\
\hline
\end{tabular}


Table 1 (continue)

\begin{tabular}{llll}
\hline Author/Year & $\begin{array}{l}\text { Study } \\
\text { origin }\end{array}$ & Model & Description \\
\hline $\begin{array}{l}\text { Hanson et al. } \\
(2006)\end{array}$ & $\begin{array}{l}\text { United } \\
\text { States }\end{array}$ & VL (in dB $)=20 \log _{10}\left(v_{m} / v_{r e f}\right)$ & $\begin{array}{l}v_{m} \text { is the measured velocity. } \\
v_{r e f} \text { is the referred velocity. } \\
\text { VL is the vibration level. }\end{array}$ \\
\hline $\begin{array}{llll}\text { Paneiro et al. } \\
(2015)\end{array}$ & Lisbon & PVS $=0.191 \log (\mathrm{V})-0.208$ & $\begin{array}{l}\text { Peak Vector Sum is in } \mathrm{mm} / \mathrm{s} . \\
\text { V is the speed of train in } \mathrm{km} / \mathrm{h} . \\
\text { D is distance in } \mathrm{m} .\end{array}$ \\
\hline
\end{tabular}

to minimize the dependency on advanced equipment when collecting data to predict the ground-borne vibrations using the developed models.

\section{MATERIALS AND METHODS}

\section{Case Study}

This research was conducted along the Kereta Api Tanah Melayu Berhad or KTMB railway track from Padang Jawa, Shah Alam, to Klang, Selangor. The railway track is a twoway railway with two (2) train routes, one to Kuala Lumpur and the other to Pelabuhan Klang, Selangor. These site locations were selected to distinguish the variety of vibration magnitudes induced by the trains running on the railway track. The sites were chosen because of the strategic locations, as there were many residential areas along the track that were endangered by the occurrence of ground-borne vibration induced by trains. This research also focused on areas with landed type residential buildings. Figure 4 shows the map of locations of study in Padang Jawa Station, Shah Alam, to Klang Station, Klang.

The route has been chosen due to the existence of landed residential buildings in the areas next to the railway track. There are no vibration barriers located along the sites. The

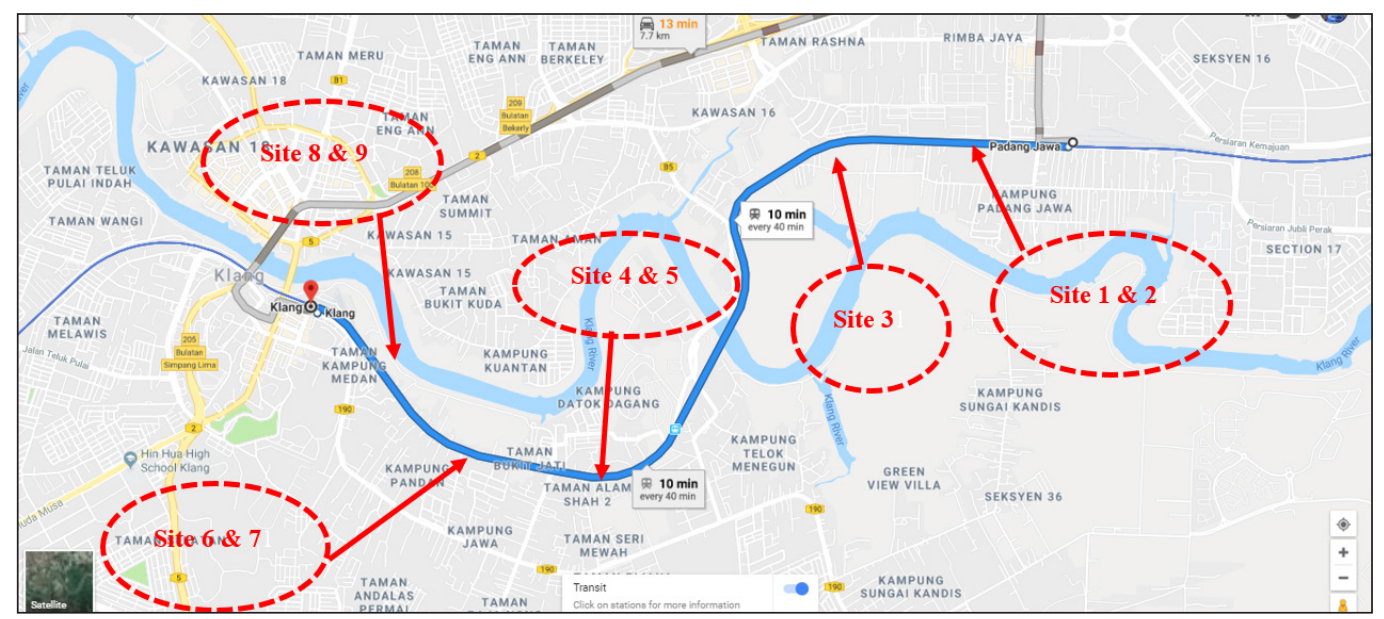

Figure 4. Map of nine sites from Padang Jawa to Klang, Selangor 
range of the distance from the residential area to the rail track for this study is less than 30 meters. Field data collected during the site survey are train parameters, the speed of the trains. The ground-borne vibration velocity measurements consist of radial vertical and horizontal wave vibrations. These measurements were obtained using a seismograph installed at the sites. As for site locations, three were chosen from Padang Jawa station to Bukit Badak Station. The other six sites chosen are located between Bukit Badak Station and Klang Station. Hence, there were nine (9) stations chosen altogether. The sites were chosen to be as close as possible to the landed residential areas. Different locations were selected to obtain various speeds of the trains and various distances from the residential areas to the sources. Shah Alam and Klang are the most developed areas and have the highest population in Malaysia.

The proposed sites are located on the Kenny Hill formation and Alluvium formation. Padang Jawa, Shah Alam, is located on the Kenny Hill formation, while Klang is on the contact boundary of Alluvium and Kenny Hill formations (Peng et al., 2004). Figure 5

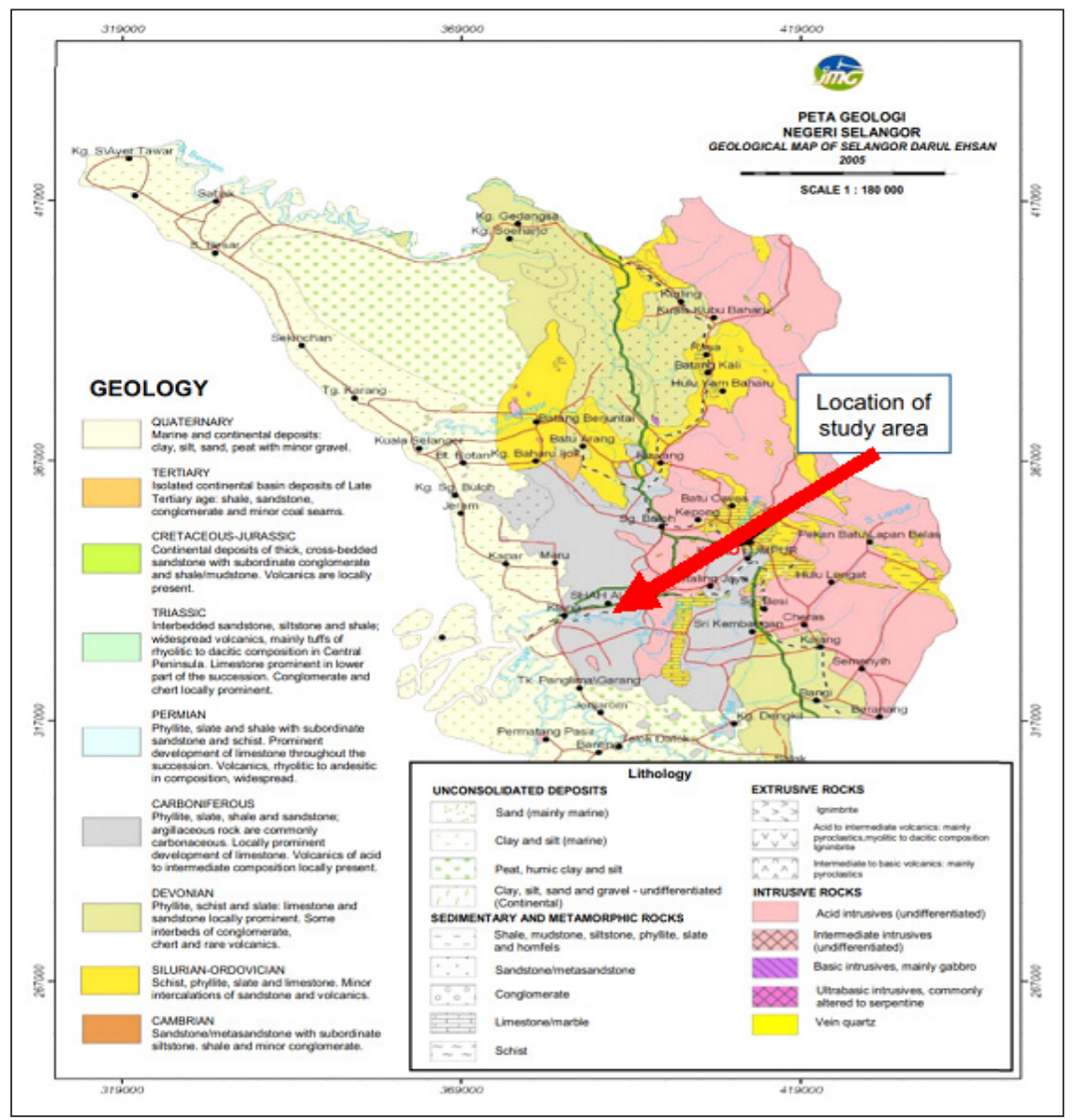

Figure 5. Geology map of studied areas located in the state of Selangor (Roslan, 2017) 


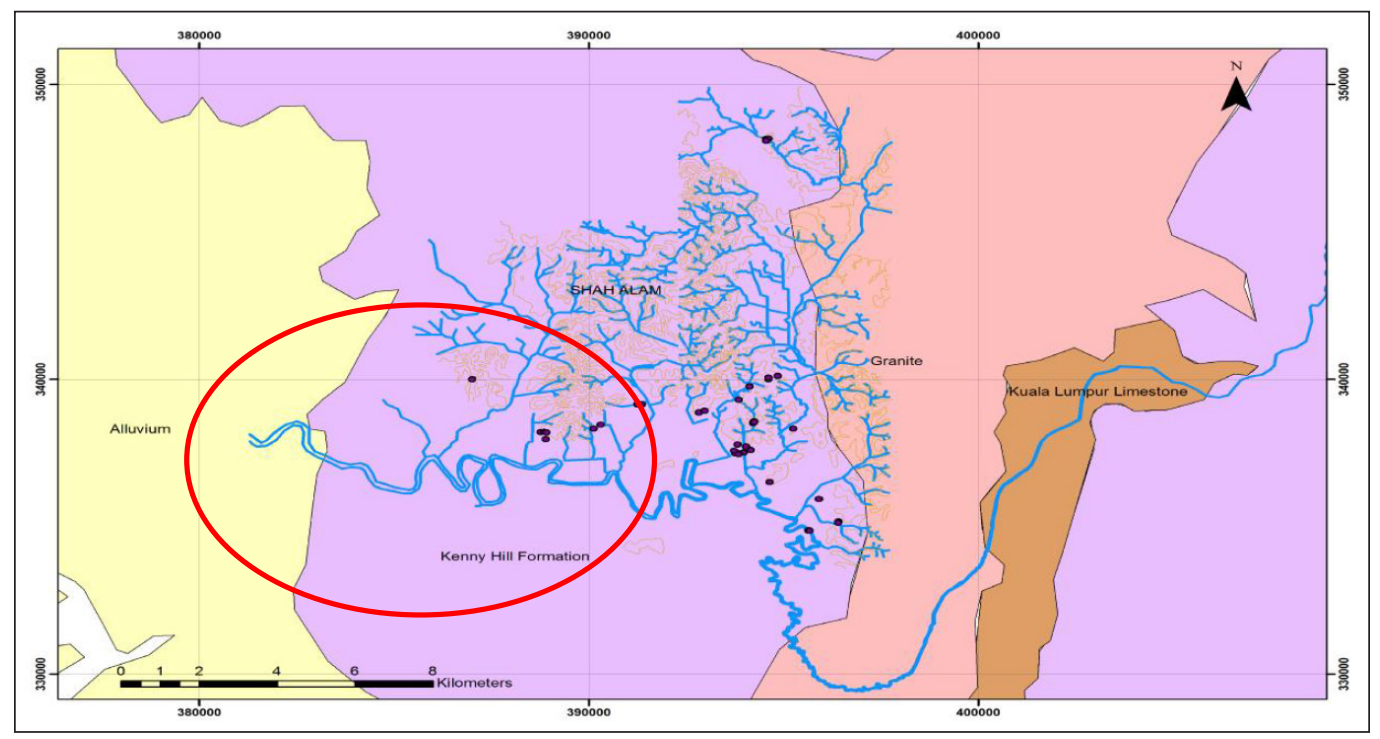

Figure 6. Close-up geological map of studied areas in Shah Alam and Klang (Peng et al., 2004)

shows the geological map of the sites chosen, and Figure 6 shows the close-up version of the geological map of the areas for this research.

Alluvial deposits typically consist of very soft to firm silty clay, with intermediate sandy layers up to $25 \mathrm{~m}$ to $30 \mathrm{~m}$ in depth. It usually consists of silty sand that lies beneath the silty slay stratum. Residual soils from Grade VI and entirely weathered materials in Grade V resulting from Quartzite weathering are only found at the depths of approximately $40 \mathrm{~m}$. The behaviour of soft alluvial soil is influenced by the source of the parent material, depositional processes, accumulation, redeposition, erosion, and fluctuations in groundwater level. In the Klang region, alluvial soil typically shows a marked stratification, and in these deposits, organic matters, like seashell and decayed wood, are often present (Tan et al., 2004).

The formation of Kenny Hill is a series of sedimentary clastic rocks consisting of interlocking shales, siltstones, mudstones, and Paleozoic upper sandstones. It is usually characterised, as seen in Klang Valley, by undulating terrain of low hills and shallow as well as broad valleys in its outcrop. The subsurface investigation recorded that along the alignment, the Kenny Hill formation is a series of interbedded siltstones, mudstones/shales, and sandstone overlaid by stiff over consolidated soil mainly of silty sand and sandy silty clay. The formation underwent metamorphic events at certain stretches resulting in changes of sandstone or siltstone to quartzite and phyllite/schist, respectively (Khoo et al., 2019). Silty clay soil or clay, defined as soft soil, is geologically young and reaches a balance under its own weight. However, it has not undergone significant secondary or delayed consolidation since its formation. This is distinguished by the fact that it can only bear the soil's overload weight, and any additional load would result in relatively large deformation. 
This classification also includes soils that have not completed consolidation under their own weight (Kempfert \& Gebreselassie, 2006). Soft soil, as claimed by Sulaiman (2018), and Cenek et al. (2012), is more affected by vibrations, especially vibrations with greater magnitudes compared to other soil types.

\section{Instrumentation and Equipment Strategy Setting Up}

Data reading and measurements of ground-borne vibration velocity were conducted for each site using a seismograph meter, also known as the Mini-Seis, produced by White Industrial Seismology Inc. A detailed illustration of the Mini-Seis location is demonstrated in Figure 7. A two-hour midnight time is set to obtain the data from the freight trains since they only operate after passenger commuter operation ends.

\section{Measurement of Train Speed}

The train parameter recorded for this research was its speed. The data were chosen as one of the parameters for this modelling since the data can be measured directly at site by recording the time taken for a train to pass a certain distance. The exact time of the train passing through the site was taken to tally with data recorded in the Mini-Seis. To get a precise speed data value from the train, the Stalker XLR Lidar radar speed gun model was used. The train speed was measured in $\mathrm{km} / \mathrm{h}$.

The freight train passed the studied sites at midnight after 12.00 a.m. and above after the end of passenger train services. Due to this condition, the data collection for freight train

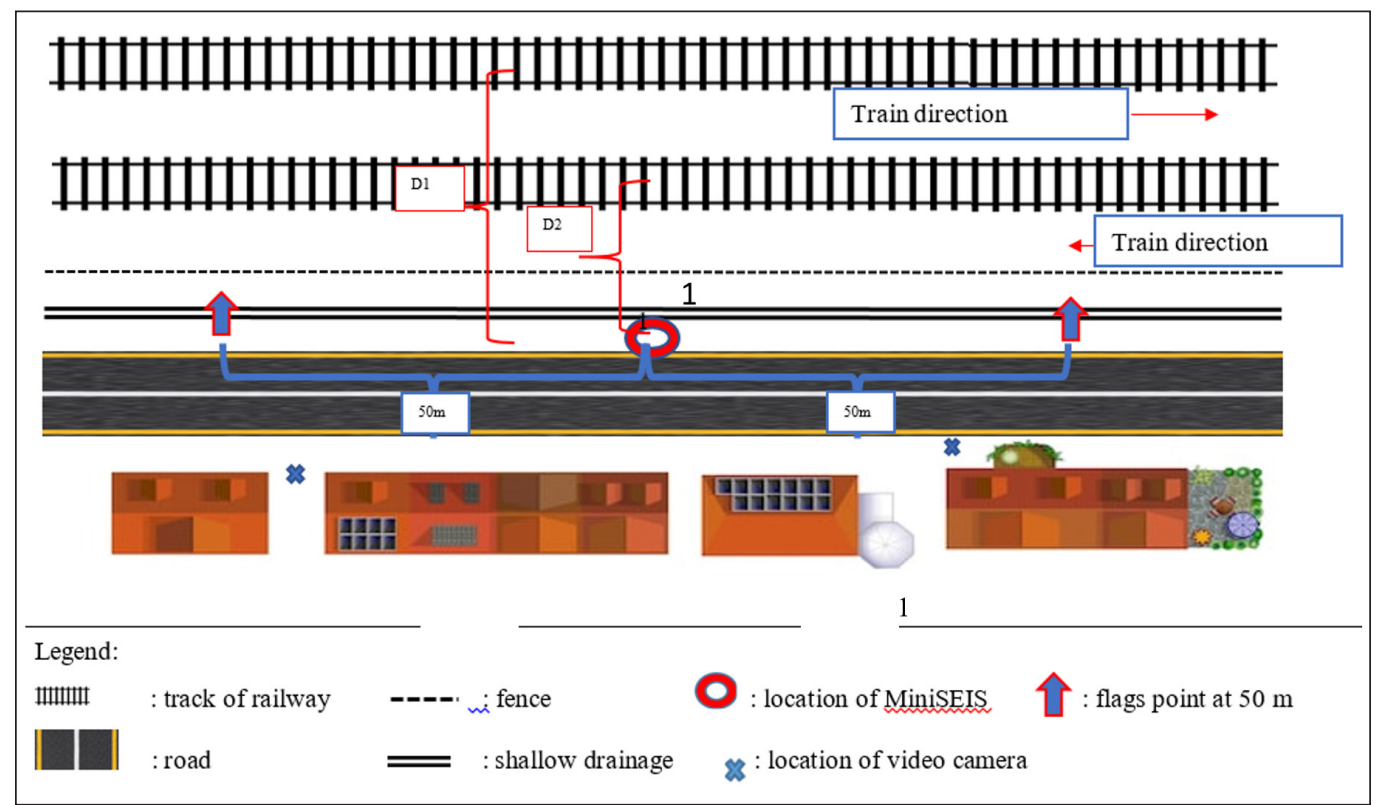

Figure 7. The location of Mini-Seis at site study at midnight session of each site 
was done from 2.00 a.m. until 4 a.m.. KTMB cargo services of diesel electric KTM Class 23 from Hitachi, KTM Class 24 by Toshiba, KTM Class 25 from Electro-Motive Diesel, ADtranz DE-AC33C model for Class 26, CKD8C, and CDK8E for Class 29 model were used for the locomotive in freight services. The axle load for the diesel-electric locomotive was 20 tonnes with the loco weight of 120 tonnes (Malay Mail, 2008). In 1996, the United Nations of Economic and Social Commission for Asia and the Pacific or known as ESCAP stated that the load restriction for a single locomotive unit in Malaysia was 1200 tonnes throughout the system (ESCAP, 1996).

\section{Measurement of Embankment Parameter}

The height and width of the ballast from the locations of this study were measured. The measurements were recorded using a laser meter and a measuring tape. The distance of the track to the receiver or the location of the Mini-Seis was also recorded. The data were then analysed to find the relationship between the dimension of the ballast with the ground-borne vibration velocity induced by trains. Additionally, the relationship between the distance from the track to the receiver (Mini-Seis) and the ground-borne vibration velocity was also analysed. A laser meter was used as an alternative to measure the distance at inaccessible locations to the researchers. It was also used to validate the distance measurement taken using a measuring tape. From the survey, it was found that the track gauge recorded was $1000 \mathrm{~mm}$, and the type of ballast from granite stone with the composite size of $14 \mathrm{~mm}$, $28 \mathrm{~mm}, 50 \mathrm{~mm}$, and $63 \mathrm{~mm}$. The height and width of ballast varied based on location within the range of $0.12 \mathrm{~m}-0.88 \mathrm{~m}$ in height and $2.38 \mathrm{~m}-3.19 \mathrm{~m}$ in width of the ballast. Figure 8 shows the main components of track which are ballast, sleeper and track rail, and the range of dimensions of ballast at site.

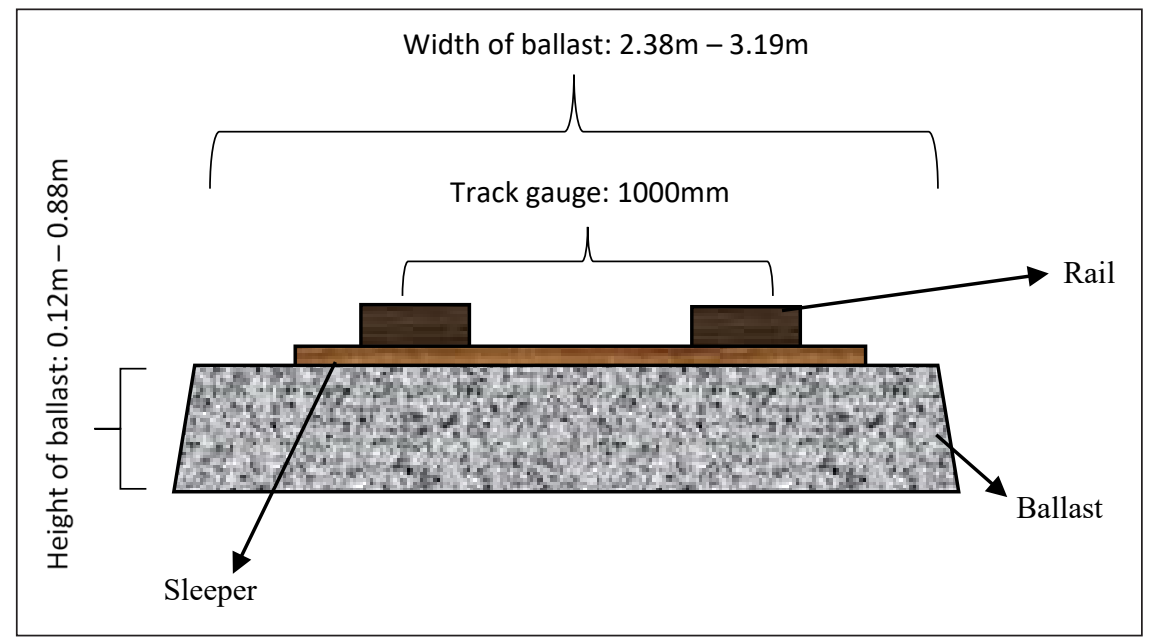

Figure 8. The main component of track with the range of dimension at site 


\section{Measurement of Ground Vibration}

With a Mini-Seis digital seismograph, ground vibration velocity was measured. A MiniSeis consists of the monitor as a data logger, a transducer of geophone, and a microphone (White Industrial Seismology Inc., 2009). The geophone and microphone transducer were mounted in residential areas on the ground and were connected to the Mini-Seis monitor as shown in Figure 9. The coordinates of the Mini-Seis were measured using a GPS meter. The time displayed by the Mini-Seis was recorded to tally with the actual time of the trains passing by the designated points to signify the data during data analysis.

As freight trains only operate at midnight after the end of passenger commuter services, the data collection using the Mini-Seis was done at midnight.

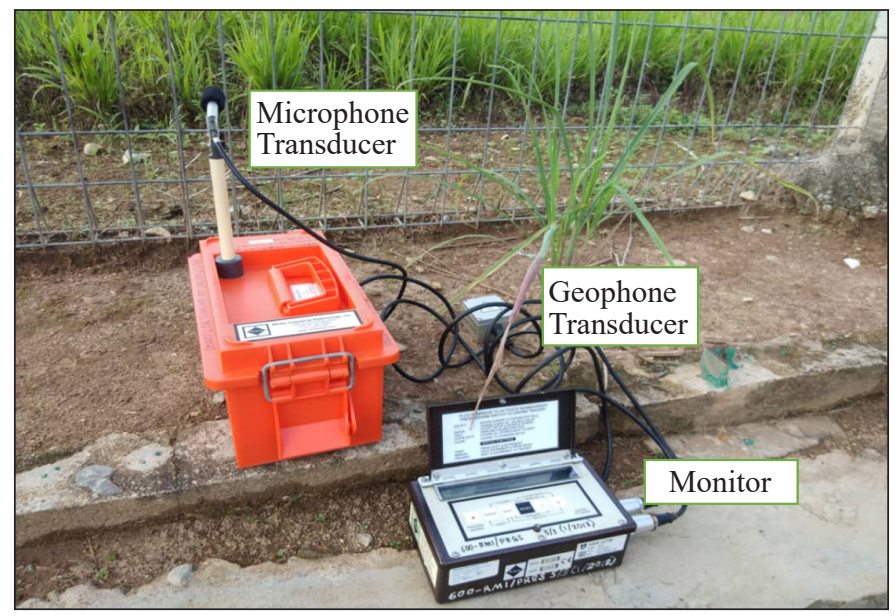

Figure 9. Mini-Seis installed at the studied site

Using the Mini-Seis via the geophone transducer, the lowest vibration velocity level that could be registered was $0.063 \mathrm{~mm} / \mathrm{s}$, and the microphone was able to measure up to $148 \mathrm{~dB}$ of sound pressure. The seismic channel consists of three longitudinal, transverse, and radial vibration velocity data readings. Using the data analysis programme given, the readings were collected. The distance was measured from the source to the receiver using the Mini-Seis. To define the relationship between the distance of the source to the receiver with the vibration frequency, different distances were calculated at the same site analysis. Those values were then used in the model development process.

\section{RESULTS AND DISCUSSION}

\section{Descriptive Statistics of the Empirical Peak Particle Velocity Data}

According to Al-Hunaidi (1994) and Roess et al. (2006), the sample size required to estimate a variable in certain confident level is as shown in Equation 1. 


$$
\mathrm{N}=\frac{1.96^{2} s^{2}}{a e^{2}}
$$

Where:

$\mathrm{N}=$ number of sample size for $95 \%$ confidence interval

$\mathrm{s}=$ standard deviation of vibration velocity

ae $=$ limit of acceptable error

The number of $1.96^{2}$ is for $95 \%$ confidence interval, which is the most common approach, to compute the precision and confidence of the sample mean as an estimator of the true mean of the underlying distribution (Roess et al., 2006). The tolerance of acceptable error (ae) is $\pm 0.05 \mathrm{~mm} / \mathrm{s}$ as stated in White Industrial Seismology Inc. (2009) for using MiniSeis, and the practical use is made based on this overall study for vibration velocities have standard deviation (s) of approximately $0.542 \mathrm{~mm} / \mathrm{s}$. A sample of 452 vibration velocities are required as shown in Equation 2 with $95 \%$ confidence interval.

$$
\mathrm{N}=\frac{1.96^{2}(0.542)^{2}}{(0.05)^{2}}=451.41 \approx 452
$$

Mini-Seis produces a peak particle velocity obtained from the ground-borne traverse, radial, and horizontal vibration velocity directions. An overview of the empirical peak particle velocity data has been encapsulated in the descriptive statistics consisting of all variables' information such as the mean value, maximum value, minimum value, median value, skewness, kurtosis value, and standard deviation. From the result produced by the descriptive statistics, extreme values can be recognized during the screening process. The collected data from the study are 772, higher than the sample size. The empirical PPV data after screening are formulated in Table 2.

Table 2

Descriptive statistics for the freight PPV

\begin{tabular}{lcccccccc}
\hline Variable & Unit & Mean & StDev & Minimum & Median & Maximum & Skewness & Kurtosis \\
\hline PPV & $\mathrm{mm} / \mathrm{s}$ & 1.395 & 0.835 & 0.191 & 1.191 & 3.461 & 1.12 & 0.58 \\
Speed & $\mathrm{km} / \mathrm{h}$ & 32.30 & 8.29 & 15.00 & 32.00 & 48.00 & 0.44 & -0.18 \\
Distance & $\mathrm{m}$ & 9.606 & 3.227 & 4.225 & 10.483 & 15.075 & -4.05 & 15.26 \\
Height of ballast (1) & $\mathrm{m}$ & 0.346 & 0.153 & 0.120 & 0.360 & 0.750 & -0.22 & -0.99 \\
Height of ballast (2) & $\mathrm{m}$ & 0.479 & 0.188 & 0.210 & 0.395 & 0.880 & 1.31 & 2.14 \\
Width of Ballast & $\mathrm{m}$ & 2.684 & 0.256 & 2.38 & 2.65 & 3.19 & 0.52 & -0.40 \\
$\begin{array}{l}\text { Depth of drainage } \\
\text { Width of drainage }\end{array}$ & $\mathrm{m}$ & 0.100 & 0.204 & 0.000 & 0.000 & 0.800 & 1.97 & 3.23 \\
$\begin{array}{l}\text { Distance of drainage } \\
\text { from receivers }\end{array}$ & $\mathrm{m}$ & 0.263 & 0.537 & 0.000 & 0.000 & 1.500 & 1.80 & 1.61 \\
$\begin{array}{l}\text { Distance of drainage } \\
\text { to sources }\end{array}$ & $\mathrm{m}$ & 2.545 & 1.233 & 0.000 & 0.000 & 5.580 & 2.56 & 7.16 \\
\hline
\end{tabular}


From Table 2, the PPV recorded from the case study is in the median of $1.191 \mathrm{~mm} / \mathrm{s}$, with the maximum data recorded of $3.461 \mathrm{~mm} / \mathrm{s}$. This data already exceeds the allowable limit stated in the guidelines for vibration limits and control from the Department of Environment Malaysia (2007). Department of Environment Malaysia states that the allowable limit for residential area is $0.567 \mathrm{~mm} / \mathrm{s}$, and $1.176 \mathrm{~mm} / \mathrm{s}$ for commercial area. This study clearly shows that the PPV recorded exceeds the limit either for residential or commercial area although the study was conducted at residential areas.

\section{Correlation Analysis for the Freight PPV Parameters}

Correlation analysis is used to diagnose the possible relationship between the dependent and independent variables used in the development of the regression models. The correlational hypotheses are described as follows:

$\mathrm{H}_{0}=$ There is no correlation between two variables.

$\mathrm{H}_{1}=$ There is a correlation between two variables.

Correlation analysis was used to determine the total possible variable combinations and the results of the overall variables as shown in the correlation matrix in Table 3. Each column consists of r-value and $p$-value. The p-values are located at the bottom of each row and the r-values are located at the top of each row.

Table 3 shows the correlation values between PPV, speed, distance, height of ballast, depth of drainage, width of drainage, and distance of drainage from receivers to sources. Since this study purposely develops an empirical model for PPV, only significant variables with PPV are considered. Significant variables with PPV are the speed and distance, and the p-values are less than 0.05 for the mentioned variables. The existence of drainage at the locations does not affect PPV since the drainage does not function as barriers as the optimum barrier depth should be in the range of 5 to 20 meters (Orehov et al., 2012). The maximum depth of drainage recorded at site was only 0.8 meter. The height of the ballast, width of ballast, as well as the distance of drainage from receivers to sources also did not have significant impact on the PPV as the p-values were more than 0.05 .

\section{Multiple Linear Regressions}

The first model for multiple linear regressions was computed with the freight PPV as the response, while the speed of train (s) and distance (d) were the predictors. Table 4 displays the constant values and the three predictors.

The hypotheses for the final estimating mode are declared as follows:

$\mathrm{H}_{0}=$ The predictor cannot be used for estimating in the PPV model.

$\mathrm{H}_{1}=$ The predictor can be used for estimating in the PPV model.

Table 4 defines the variables for model of freight trains which are significant with the independent variables in predicting the PPV, where the p-values of the multiple linear 
Empirical Model of Ground-borne Vibration from Freight Train

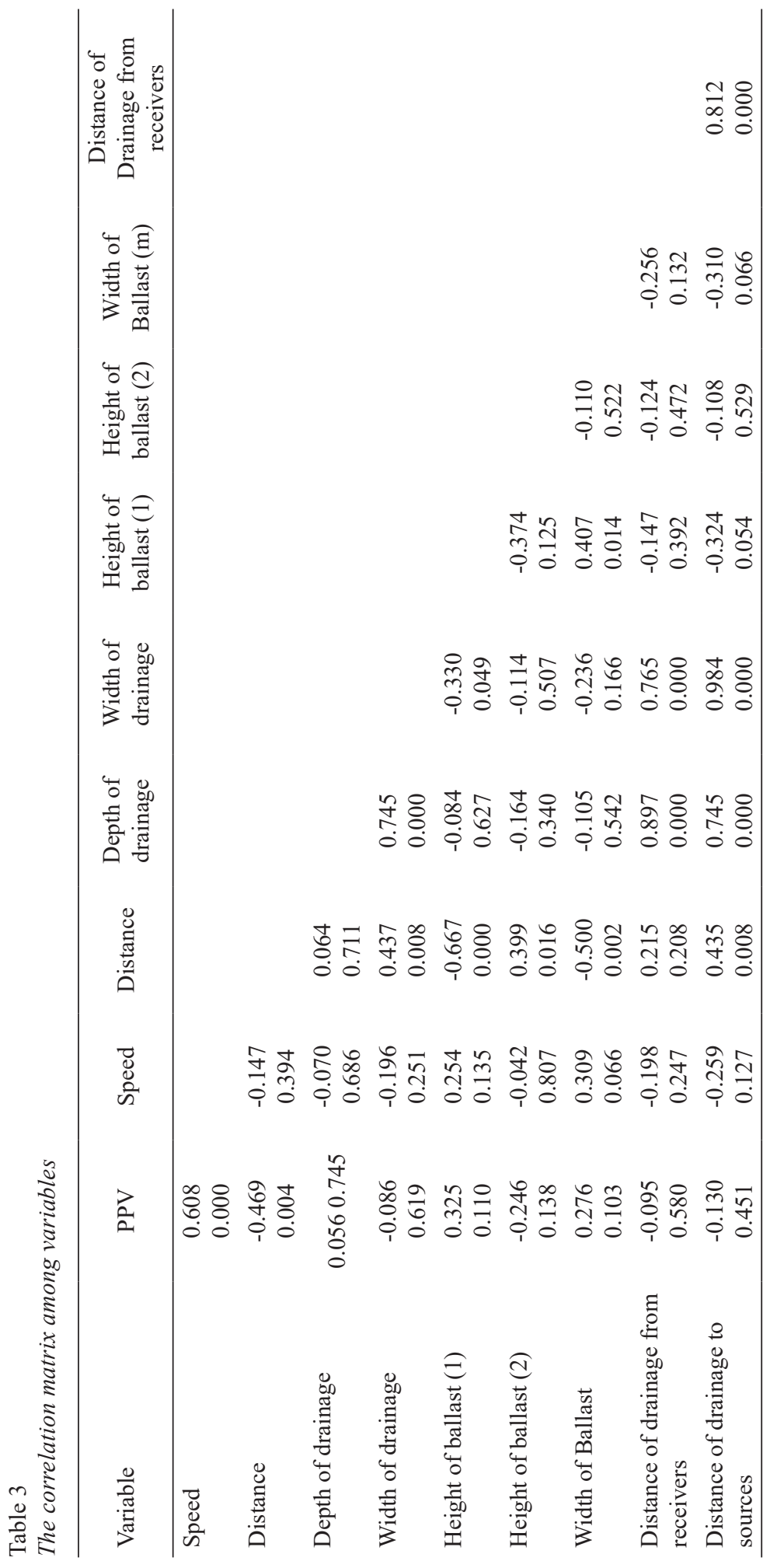


Table 4

Multi-linear regression model for freight PPV

\begin{tabular}{lcccccc}
\hline Predictor & Coef & SE Coef & T & P & S & R-Sq \\
\hline Constant & 0.5540 & 0.5461 & 1.01 & 0.3128 & & \\
Speed & 0.05553 & 0.01232 & 4.51 & 0.000 & 0.597443 & $51.7 \%$ \\
Distance & -0.10029 & 0.03163 & -3.17 & 0.003 & & \\
\hline
\end{tabular}

Table 5

ANOVA for the model of freight trains

\begin{tabular}{lccccc}
\hline Source & DF & SS & MS & F & P \\
\hline Regression & 2 & 12.6041 & 6.3020 & 17.66 & 0.000 \\
Residual Error & 33 & 11.7790 & 0.3569 & & \\
Total & 35 & 24.3831 & & & \\
\hline
\end{tabular}

regression are smaller than 0.05 . This indicates that the null hypothesis $\left(\mathrm{H}_{0}\right)$ is rejected, and the alternative hypothesis $\left(\mathrm{H}_{1}\right)$ is supported. Therefore, in the model to estimate the freight train PPV, these predictors could be used. The standard error of the constant value coefficient is 0.5540 , the speed value is 0.05553 , and distance is -0.10029 . Due to the small values of the standard error for each variable, the values are dependable in predicting the population parameter. The R-squared $\left(\mathrm{R}^{2}\right)$ and the square root of the mean square error $(\mathrm{S})$ determine how fit the model is against the collected data (Minitab, 2010). Table 4 shows that the $\mathrm{S}$ value is 0.597443 , which represents the prediction of the variance of data in the linear relationship between the predictor and the response. $\mathrm{R}^{2}$ is used to regulate the linear relationship between the predictor and the response. The $\mathrm{R}^{2}$ value used for the development of the model is $51.7 \%$ of the variations.

Table 5 shows the Analysis of Variance (ANOVA) allocation of the output. The hypotheses for this test are described as follows:

$\mathrm{H}_{0}=$ The PPV model cannot be used for estimating.

$\mathrm{H}_{1}=$ The PPV model can be used for estimating.

Table 5 proves that the $\mathrm{p}$-value is less than the $\alpha$-level which is 0.05 leading to the acceptance of the $\mathrm{H}_{1}$ and the rejection of the $\mathrm{H}_{0}$. Therefore, the regression model is deemed significant, and could be used to elaborate or forecast the freight train PPV if the empirical data of the speed and distance are used. In conclusion, the model of estimation is developed as shown in Equation 3 in the form of regression equation for the freight PPV,

$$
\mathrm{PPV}_{\text {Freight }}=0.554+0.0555 s-0.100 d
$$

Where:

$\mathrm{PPV}_{\text {Freight }}=$ Peak Particle Velocity $(\mathrm{mm} / \mathrm{s})$ for freight type of train 
$s=$ Speed of train $(\mathrm{km} / \mathrm{h})$

$d=$ distance of receiver to sources (m)

The Equation 3 shows that the important variable coefficient for this model is the speed which has a positive sign. This implies that the increase of speed leads to an increase in PPV, while the decrease between the receivers and the sources results in the decrease in PPV. This pattern of model is similar to the findings made by Paneiro et al. (2015) when only speed and distance are considered as the parameters for model development.

\section{Justification of the Regression Model Assumptions for Freight Train Model}

The next step involved was the residual plot verification process to decide whether the model was appropriate, and the regression projection was identified. The characteristics between the fitted response values and the response values observed were the residual plots. Figure 10 shows the residual versus fit value plot for freight train PPV. From Figure 10 , residual plot tends to scatter randomly, and the plot is scattered close to the horizontal line in correspondence to approximately zero residuals. Hence, the proof of missing terms or non-constant variance does not exist (Minitab, 2010).

\section{Normality Test for Residuals of Freight PPV Prediction Model}

The goodness-of-fit test and probability plot, such as the Kolmogorov-Smirnov and Anderson-Darling normality tests, determine whether the residuals were normally distributed. Figures 11 and 12 show that the points are scattered closely around the straight line which show that the residuals are normally distributed.

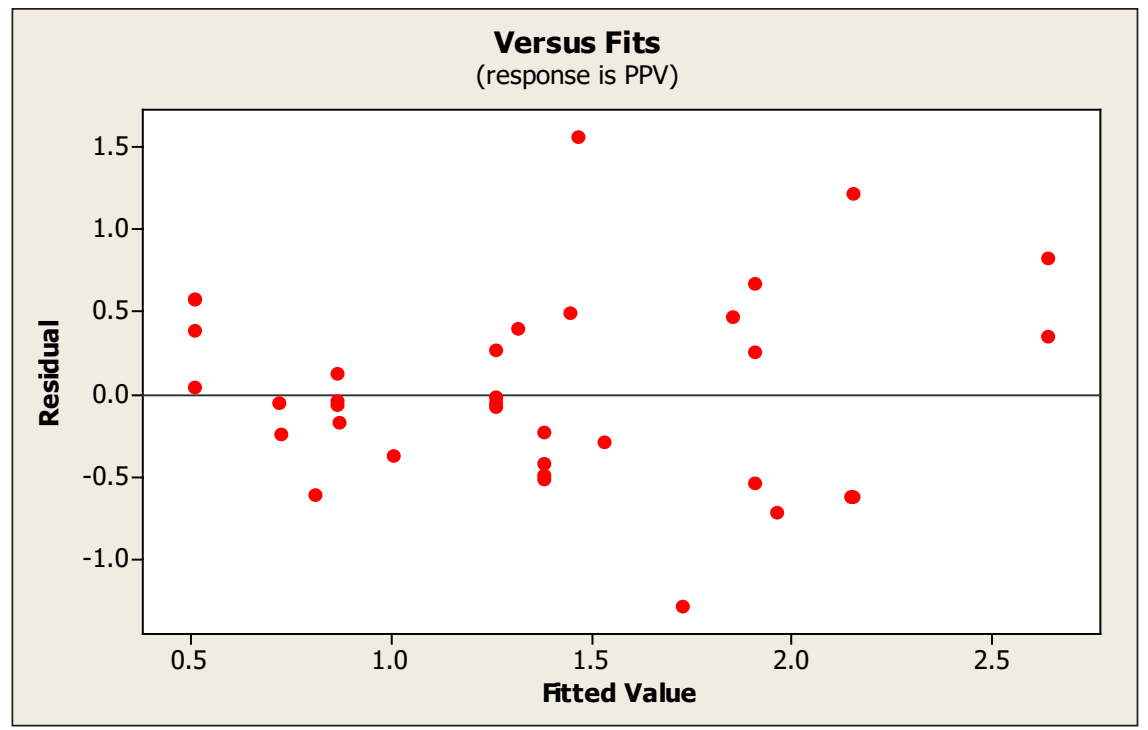

Figure 10. Residual versus fit value plot for freight PPV prediction model 


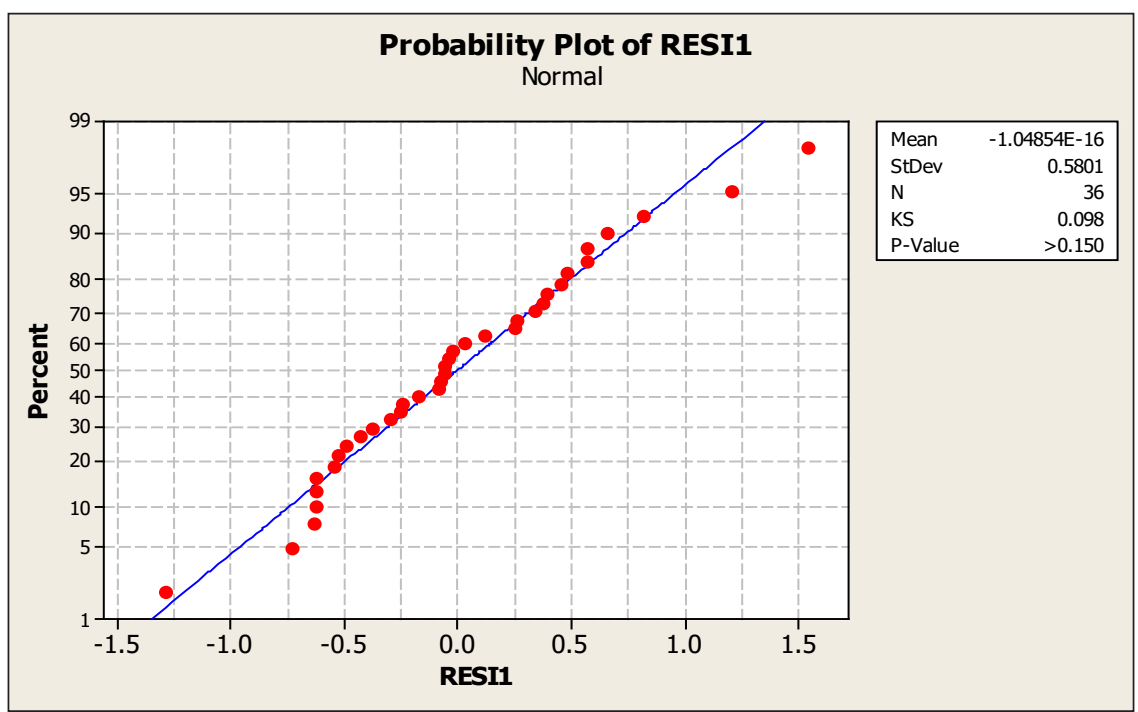

Figure 11. Kolmogorov-Smirnov normality test for freight PPV prediction model

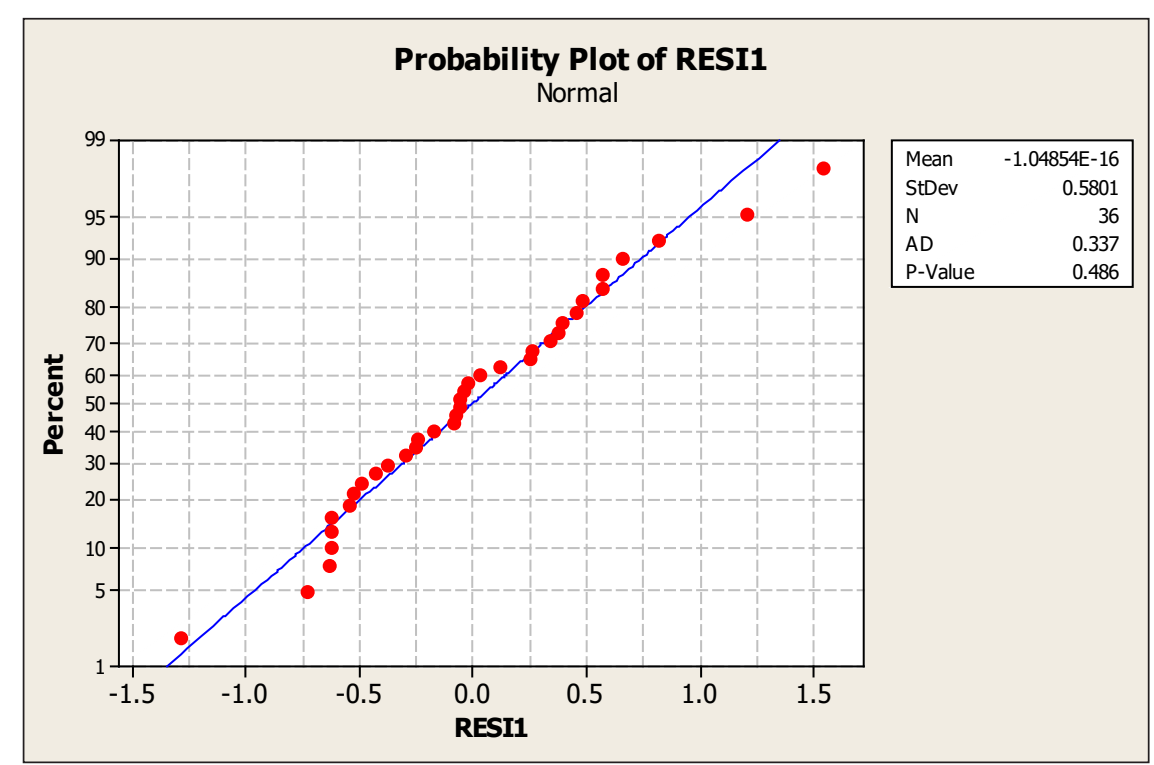

Figure 12. Anderson-Darling normality test for freight PPV prediction model

The tests of hypotheses for Anderson-Darling and Kolmogorov-Smirnov normality tests are described as follows:

$\mathrm{H}_{0}=$ The residuals for the predicted model are normal.

$\mathrm{H}_{1}=$ The residuals for the predicted model are not normal.

Since the p-values of the Anderson-Darling and Kolmogorov-Smirnov normality tests are more than 0.05 , the $\mathrm{H}_{0}$ is accepted, and the residuals follow a normal distribution curve. 


\section{MODEL VALIDATION}

The developed PPV model for freight trains must be evaluated to determine the ability of the model to represent the actual situation and condition to describe the presence of variability in a sample other than the set used for the model development.

\section{Scatterplot of the Freight Model}

Figure 13 shows the relationship between the empirical PPV and the predicted PPV for freight trains developed in this research. Figure 13 demonstrates that the points of predicted PPV versus empirically scattered PPV are close around the straight line, indicating that the PPV of the predicted model for freight train can be accepted.

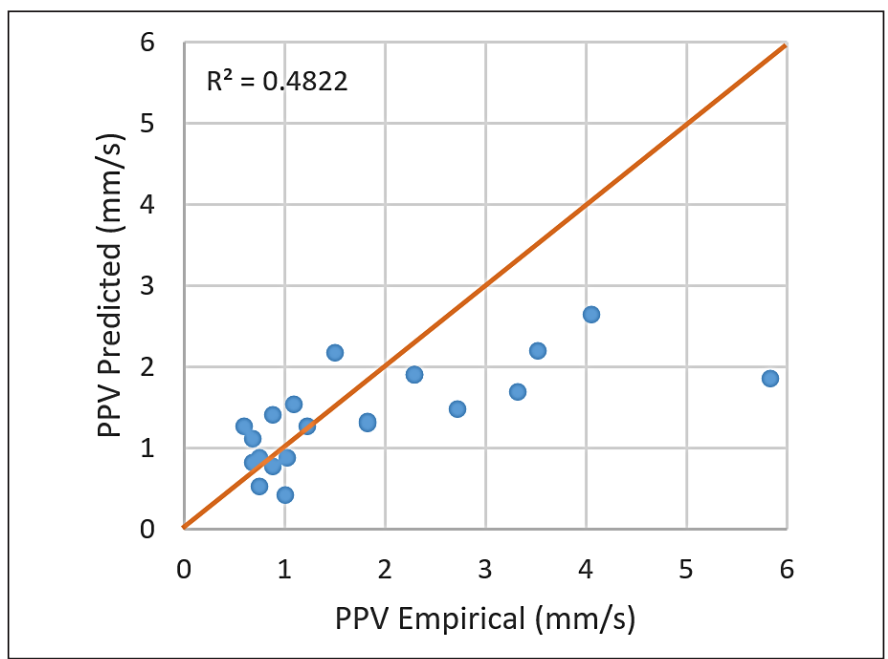

Figure 13. Predicted PPV versus empirical PPV

Where PPV empirical is denoted as empirical PPV $(\mathrm{mm} / \mathrm{s})$, and PPV predicted using Equation 1 is denoted as predicted PPV $(\mathrm{mm} / \mathrm{s})$.

\section{RSME, MAE, AND MAPE OF PPV MODEL}

Table 6 shows the comparison of RMSE, MAE, ad MAPE of the PPV for freight train predicted model. As shown in Table 6, the deviation of RMSE from the empirical value of $\mathrm{PPV}$ is $0.9712 \mathrm{~mm} / \mathrm{s}$, while the deviation of MAE from the empirical value of PPV is 0.7422 $\mathrm{mm} / \mathrm{s}$. The MAPE for the empirical value of PPV is $27.2 \%$. Thus, it can be summarised that due to the limited difference values of the RMSE, MAE, and MAPE, the PPV model for freight trains is appropriate to estimate the PPV.

Table 6

RMSE, MAE, and MAPE for PPV freight

\begin{tabular}{lccc}
\hline MODEL & RMSE $(\mathrm{mm} / \mathrm{s})$ & MAE $(\mathrm{mm} / \mathrm{s})$ & MAPE $(\%)$ \\
\hline PPV Freight & 0.9712 & 0.7422 & 27.154 \\
\hline
\end{tabular}




\section{Comparison of Mean for Predicted PPV with Empirical PPV using Paired T-Test}

The mean comparison was completed between the PPV from the data observed by taking the validation data set and the predicted PPV as shown in Table 7. The alternative and null hypotheses are as follows:

$H_{0}=$ The mean difference for the model is equal to zero.

$H_{l}=$ The mean difference for the model is not equal to zero.

The p-value is 0.055 , which is greater than 0.05 as shown in Table 7 , suggesting that the null hypothesis $\left(H_{0}\right)$ is not rejected at the significance level of 5\%. This shows that the PPV of the projected commuter train model does not vary much from the empirical PPV values.

Table 7

Validation analysis result for PPV from freight model

\begin{tabular}{lc}
\hline Test & Vab \\
\hline t-statistic & 2.04 \\
p-value & 0.055 \\
\hline
\end{tabular}

\section{CONCLUSION}

Based on the Equation 3 model developed in the multiple linear regressions, it is established that PPV of the ground-borne vibration velocity could be calculated using the speed of the trains and the distance from the receiver to the sources. It is found that PPV of the groundborne vibration velocity increases almost linearly when the speed of the train increases. From the regression model, it is discovered that the distance of the receivers (residential areas) to the sources (train tracks) produces a reverse effect on the PPV of the groundborne induced by freight trains. From Equation 3, when the distance increases, the PPV of ground-borne vibration velocity tends to decrease. The closer the residential houses to the track, stronger ground-borne vibration can be felt by the residents. To summarise, the model developed has been proven to be able to predict the peak value of ground-borne vibration velocity induced by freight trains. The model development and other findings can be used in future research but limited to the characteristics based on the scopes of this study. Practitioners can use the model by using minimal number of tools or even without tools to predict the vibrations induced by freight trains at studied sites. The developed model is user-friendly and easy to use. In addition, it is reliable because the model undergoes the validation and calibration processes. The model developed acts as a bridge between the theoretical knowledge and the actual implementation.

\section{ACKNOWLEDGEMENT}

The authors would like to thank the authorities from the Faculty of Civil Engineering, Universiti Teknologi MARA (UiTM) for their constant support and encouragement. Appreciation goes to the Research Management Institute (RMI, UiTM) and Ministry of 
Higher Education Malaysia (MOHE) for the financial support's FRGS Grant scheme: RMI File No: 600-IRMI/FRGS 5/3 (008/2019), Sponsorship File No: FRGS/1/2018/SKK06/ UITM/02/5.

\section{REFERENCES}

Alcudia, A. D., Stewart, R. R., Eliuk, N., \& Espersen, R. (2007). Vibration and air pressure monitoring of seismic sources. CREWES Research Report, 19, 1-14.

Al-Hunaidi, M. O. (1994). Evaluation of appropriate sample size for measurement of vibration levels induced by rail transit vehicles. Canadian Acoustics, 22(3), 181-182.

Avellan, K., Belopotocanova, E., \& Puurunen, M. (2017). Measuring, monitoring and prediction of vibration effects in rock masses in near-structure blasting. Procedia Engineering, 191, 504-511. https://doi. org/10.1016/j.proeng.2017.05.210

Bahrekazemi, M. (2004). Train-induced ground vibration and its prediction ( $\mathrm{PhD}$ thesis). Royal Institute of Technology, Stockholm, Sweden. Retrieved September 29, 2019, from http://www.gatewaycog.org/media/ userfiles/subsite_9/files/rl/HSRReferenceMaterialsReportsMapsandOtherHSTSections/References-TrainInduced_Ground_Vibration_and_Its_Prediction_2004.pdf

British Standard. (2008). BS 6472-1: Measurement and evaluation of human exposure to whole-body mechanical vibration and repeated shock. Retrieved September 19, 2019, from https://www.standardsuk.com/products/ BS-6472-1-2008

Cenek, P. D., Sutherland, A. J., \& McIver, I. R. (2012). Ground vibration from road construction (No. 485). The National Academies of Sciences, Engineering, and Medicine.

Deutsches Institut für Normung. (1999). DIN 4150-3: Structural vibrations - Part 3: Effects of vibration on structures. Retrieved September 19, 2019, from https://codehub.building.govt.nz/resources/din-41503-1999/

Department of Environment Malaysia, (2007). The planning guidelines for vibration limits and control in the environment. Ministry of Natural Resources and Environment. . Retrieved October 2, 2018, from https:// environment.com.my/wp-content/uploads/2016/05/Vibration.pdf

Eitzenberger, A. (2008). Train-induced vibrations in tunnels-A review, division of mining and geotechnical engineering, Department of Civil, Mining and Environmental Engineering, Luleå University of Technology (Technical Report). Retrieved September 30, 2019, from https://www.diva-portal.org/smash/get/ diva2:996052/FULLTEXT01.pdf

ESCAP. (1996). Trans-Asian railway route requirements: development of the Trans-Asian railway in the IndoChina and ASEAN subregion volume 2. United Nation Economic and Social Commission for Asia and the Pacific. Retrieved January 30, 2020, from https:/www.unescap.org/sites/default/d8files/knowledgeproducts/Trans-Asian-Railway-Route-Requirements-Volume-2.pdf

Garg, P. (2017). Displacement measurement using a laser Doppler vibrometer mounted on an unmanned aerial vehicle (Master dissertation). University of the New Mexico, USA. Retrieved September 19, 2019, from https://digitalrepository.unm.edu/cgi/viewcontent.cgi?article=1392\&context=ece_etds 
Hajek, J. J., Blaney, C. T., \& Hein, D. K. (2006, September 17-20). Mitigation of highway traffic-induced vibration. In 2006 Annual Conference of the Transportation Association of Canada (pp. 1-13). Charlottetown, Prince Edward Island, Canada.

Hanson, C. E. ,Tower, D. A., \& Mesiter, L. D. (2006). Transit noise and vibration impact assessment. Office of Planning and Environment, Federal Transit Administration (FTA). Retrieved June 02, 2020, from https:// docs.vcrma.org/images/pdf/planning/ceqa/FTA_Noise_and_Vibration_Manual.pdf

Hemsworth, B. (2000). Reducing groundborne vibrations: state-of-the-art study. Journal of Sound and Vibration, 231(3), 703-709. https://doi.org/10.1006/jsvi.1999.2642

Huang, Z. (2016). Intergrated railway remote condition monitoring (Doctoral dissertation). The University of Birmingham, England. Retrieved June 20, 2019, from https:/etheses.bham.ac.uk/id/eprint/7904/1/ Huang17PhD.pdf

Hunt, H. E., \& Hussein, M. F. (2007). Ground-borne vibration transmission from road and rail systemsprediction and control. In M. J. Crocker (Ed.), Handbook of Noise and Vibration Control (pp. 1458-1469). John Wiley \& Sons, Inc.

ISO. (1997). ISO 2631-1:1997(en) Mechanical vibration and shock - Evaluation of human exposure to whole-body vibration - Part 1: General requirements. International Organization for Standardization. Retrieved September 19, 2019, from https://www.iso.org/standard/7612.html

Jiang, T., \& Zhang, X. (2004, August 1-6). In situ experiments and numerical assessment of environmental vibration induced by urban viaduct rail transit in Shanghai. In 13th World Conference on Earthquake Engineering, Canada. (pp. 1-11). Vancouver, Canada.

Jones, C. J. C., \& Block, J. R. (1996). Prediction of ground vibration from freight trains. Journal of Sound and Vibration, 193(1), 205-213. https://doi.org/10.1006/jsvi.1996.0260

Kempfert, H. G., \& Gebreselassie, B. (2006). Material properties of soft soils. In excavations and foundations in soft soils (pp. 11-55). Springer Science \& Business Media.

Khoo, C. M., Gopalan, T., Rahman, N. A. A., \& Mohamad, H. (2019). volume loss caused by tunnelling in Kenny hill formation. International Journal, 16(54), 164-169. https://doi.org/10.21660/2019.54.8316

Lazi, M. K. A. M., Mustafa, M., \& Abd Rahman, Z. (2016). Assessing pedestrian behavior and walking speed on staircase: A Review. In M. Yusoff, N. Hamid, M. Arshad, A. Arshad, A. Ridzuan \& H. Awang (Eds.), International Civil and Infrastructure Engineering Conference (InCIEC) (pp. 1019-1029). Springer. https://doi.org/10.1007/978-981-10-0155-0_85

Madshus, C., Bessason, B., \& Hårvik, L. (1996). Prediction model for low frequency vibration from high speed railways on soft ground. Journal of sound and vibration, 193(1), 195-203. https://doi.org/10.1006/ jsvi.1996.0259

Malay Mail. (2008, October 10). Your voice readymade train wreck. Malay Mail. Retrieved August 8, 2019, from https://web.archive.org/web/20081013081610/http://www.mmail.com.my/Readymade_train_wreck.aspx.

Minitab. (2010). Minitab statistical software, release 16 for windows, State College, Pennysylvania. Retrieved February 15, 2019, from https://www.minitab.com/en-us/products/minitab/ 
Orehov, V. V., Moghanlou, R. N., Negahdar, H., \& Varagh, A. M. B. (2012, September 24-28). Investigation effects of trench barrier on the reducing energy of surface waves in soils. In 15th World Conference on Earthquake Engineering (pp. 24-28). Lisbon, Portugal.

Paneiro, G., Durão, F. O., e Silva, M. C., \& Neves, P. F. (2015). Prediction of ground vibration amplitudes due to urban railway traffic using quantitative and qualitative field data. Transportation Research Part D: Transport and Environment, 40, 1-13. https://doi.org/10.1016/j.trd.2015.07.006

Peng, L. C., Leman, M. S., Hassan, K., Nasib, B. M., \& Karim, R. (2004). Stratigraphic Lexicon of Malaysia. Geological Society of Malaysia.

Persson, N. (2016). Predicting railway-induced ground vibrations. LUND University. February 02, 2019, from http:/www.byggmek.lth.se/fileadmin/byggnadsmekanik/publications/tvsm5000/web5212.pdf

Roess, R. P., Prssas, E. S., \& McShane, W. R. (2006). Traffic engineering (3rd Ed.). Prentice Hall, Inc.

Roslan, N. (2017). The potential susceptibility of urban hardrock aquifers to hydraulic and contaminan stresses: The case of Shah Alam, Malaysia (Doctoral dissertation). The University of Birmingham, England. Retrieved September 29, 2019, from https://core.ac.uk/download/pdf/79609683.pdf

Sakaue, S., Yao, H., \& Suzuki, T. (2012). Applied MEMS Micro-vibration Sensors and Structural Health Monitoring. Technologies Supporting Society and Industry, 58(1), 32-47.

Suhairy, S. A. (2000). Prediction of ground vibration from railways. SP Swedish National Testing and Research Institute. Retrieved January 10, 2019, from http://doutoramento.schiu.com/referencias/outras/ Suhairy,\%20Sinan\%20al.pdf

Sulaiman, N. (2018). Empirical modelling of ground-borne vibration from road traffic. (Unpublished Doctoral dissertation). University Putra Malaysia, Malaysia. Retrieved October 10, 2019, from http://psasir.upm. edu.my/id/eprint/67898/1/FK\%202018\%2033\%20IR.pdf

Tan, Y. C., Gue, S. S., Ng, H. B., \& Lee, P. T. (2004, March 16-18). Some geotechnical properties of Klang clay. In Malaysian Geotechnical Conference (pp. 1-7). Sheraton Subang, Malaysia.

Watts, G. R. (1990). Traffic induced vibrations in buildings (Research report 246). Transport and Road Research Laboratory, Crowthorne, Berkshire. Retrieved June 06, 2019, from https://www.yumpu.com/en/document/ view/25243865/traffic-induced-vibrations-in-buildings-g-r-watts-department-for-

White Industrial Seismology Inc. (2009). Mini-seis digital seismograph: Operating manual. Retrieved October 20, 2019, from https:/whiteseis.com/MemberPages/docspecs/Mini-Seis\%20Manual.pdf

With, C., Bahrekazemi, M., \& Bodare, A. (2006). Validation of an empirical model for prediction of traininduced ground vibrations. Soil Dynamics and Earthquake Engineering, 26(11), 983-990. https://doi. org/10.1016/j.soildyn.2006.03.005 
